\title{
Basic Skill Training and Individual Expression in Basic Course of Painting
}

\author{
Jun Sun \\ School of Fine Art \\ Huanggang Normal University \\ Huanggang, Hubei, China 438000
}

\begin{abstract}
In the basic course teaching at undergraduate level, students in the learning of basic courses of painting often meet how to deal with the problems of basic skill training and personal development and how to correctly combine these two things is the important problem to be solved in teaching and learning. Because the relationship between the two is complementary each other, we should pay attention to the training of basic skills, constantly divergent thinking and develop personality, so that one painting work has his own unique style in the accumulation of painting experience.
\end{abstract}

Keywords-basic skill; personality; innovative law

\section{INTRODUCTION}

Painting, as a kind of fine art, has its own laws and forms. Its development is a historical process, reflecting an era, a society, a class, but it generally is a art. Its existence is to describe and create beauty to let people enjoy the beauty in spirit and vision. In college, how to treat painting, paying attention to the training of basic skills or emphasizing the expression of personality, is a problem which has been discussed in painting teaching.

\section{BASIC SKILls TRAINING IN BASIC COURSE OF PAINTING}

We often say that the basic skills training mainly refer to the developing and training of the basic theory of painting and basic skills knowledge. Basic training of undergraduate course in painting mainly contains the training of composition, modeling, structure, light and shade, cold or warm colors, and empty and solid strokes. And there also has a part is completed by sketching and copying.

The basic skill training is a long-term process that everyone who studies painting must go through. Michelangelo, a master of modern painting, practiced sketch since his childhood. His works of sketch and hasty sketch are numerous and behind every masterpiece have a lot of drafts of sketch and hasty sketch as a basis. His in-depth knowledge is the source of success, such as Day, Night, Dawn and Dusk, which were created by a lot of accumulations of sketch and hasty sketch, and he would practice them until the end of art. Every masterpiece is not a shell, and it is truly admirable for their solid basic skills.
Composition of basic skills training aims to cultivate one's visual ability in the early period of painting. When painting a picture, the first problem to be solved is to decide which place we should put objects in canvas. And the capability of the visual and feel must be gained by a large number of basic skills training.

When we perform a drawing object, we should have a thorough understanding of the external and internal structure, so that it is accurate. If just blindly express external, we get nothing, so we have to thoroughly understand its essence. And the understanding of the process is the basic skill training.

In the training phase of basic skills of color, we mainly focus on the feeling of color, which may inevitably have innate sense of color, and what we train is a kind of color sensitivity. The color and shape is interlinked in method. Good color can transfer more abundant spiritual information about more interesting feelings. If isolation is about cold or warm colors, sense of form, form of color, then it cannot be clear. Good color has its own life and own breath. It is just like a good shape which is generated on the canvas, not made out. We should train the ability from real things into sense of art, seeing a group of colors to the screen is a creative process, no modern pattern. In other words, as Zheng Banqiao said: "Under the pen of the bamboo is not chest of the bamboo, bamboo in the chest is not in the eyes of bamboo." Sometimes, sketch is a kind of creation, whose feeling of color is simple, while the feeling included is abundant, such as a cement under the sunshine with white smoking drying ----strong in visual and dazzling in projection. But just in such a simple color, we can see chocking cement, rougher life, stress and anxiety, and these are reflected by the process of color in tone and writing switched to from the other concept. The choice of color often affect the designed to bring the final effect, but refused the hard-edged avant-garde, and this "degree" is needed to have thick color basic skills to control.

\section{PERSONAL EXPRESSION IN PAINTING}

In the process of painting, we did not oppose the learning of specific skills. We know that only thorough the learning and master of language, we can better understand the charming of language. "We learn a language is to speak, and learn language skill is to more clearly express the complex, delicate and rich emotional world, we cannot as "language" as "language". We can not give up speaking just because we cannot express or 
express clearly, because of the enigmatic language skills."[1] We learn the basic skill of painting is to better express feelings inside. If we practice just according to the original pattern, what we get is manufactured goods, and so on there is no difference between painter who is good at copy imitate and us.

Personality is a person's characteristics in thought, based on the root of art, and is the survival of a thriving. There is no room for any similarities and repetitions, for any forms of abandoned stylization and conceptualization. The quality of art is personalized image thinking; the creation of art is the spirit of personalized products. It is often extremely conceited as the "only this one, no other stores". "The character of art is kept eternal life of youth by constant discover, enterprise and transcendence. Personality cannot be demanding also cannot be sustained, and it is accumulation and nutrition based on self-improvement, then success will come when conditions are ripe." $\left.{ }^{2}\right]$ The expression of individuality in the painting is the sublimation of the painting art to a certain stage, the performance of the way.

"The fine arts heroes" of the Italian Renaissance, the personality of painting is more populated. There is full of philosophical thinking in Leonardo da Vinci's paintings, tragic passion in Michelangelo's works, bright color, soft light and quiet-elegant rhythm in Raphael's works. In the 18th century industrial revolution, if artists, like Monnai, do not put their ideas and consciousness showed on a piece of paper, but simply continue the old group of traditional painters' bronze world to rule sun out, then how today's painting is. Sometimes, personality will be inadvertently revealed, then along this feeling of continuous improvement becomes a kind of characteristics. Every painter will have a piece of painting which he is good at, if we find that his own personalities and continuously develop it, it will become his. The works of Wang Wei and Ma Gang have similar thinking and attention, although there are different materials and styles. Ma Gang's Middle of a Chess Game paints a pair of lovers or couples, which artistic pursuit is used typical form of fine brushwork figure. It deliberately depicts the inner world of the character with a concise calligraphy, with a pure tone and with a waitand-see attitude. The characters in painting take sit or stand. Prop in the environment is a horizontal and a vertical and puts all the images around the scene. The view of the center screen is empty, intending to emphasize the sense of vagueness and emphasizing the sense of form to reflect the cleverest moment of art's conception, and it also the painter's pursuit of creativity and personality. Wang Wei's Yesterday is also drawn materials from the contemporary youth, the images of the characters in the performance are similar to the portraits of the art expression, but the tone is different from Middle of a Chess Game. The former has an avoidance and depression to the reality, and the latter has a sense of facing reality. In character's psychological and emotional characterization, the suspect in the eyes is replaced by a firm look. Although both are pictured in static state, the latter is slightly moving in the static. In the artistic language, the former is pure fresh, while the latter is more abundant. Yesterday's skills are more thorough, the description is exquisite, the technique is in place, and the effect is good, which is a point to the traditional technique of the orthodox school. Facing the anxiety, eager for quick success, speculation and blind action of packaging, they are not contaminated and they concentrate on themselves to stand inside art of thinking and explore in the new historical process. The content is same while the final effect is different. Everyone's writing style is performed in the process of creation, which is the embodiment of the personality of the artists. Though artists imply their personalities in their works, just the way of expression is different. Some artists focus on the techniques of expression, some focus on the forms, but no matter what kind of expressions, they cannot abandon the essence which painting is for people to enjoy the beauty and give the visual of beauty. We cannot be far away from the reality, society, morality and law. The innovative rule of art is generally from having to non-having, then from non-having to having, which cannot break away from general sense of order and cannot lose spiritual task entrusted by society. Art will be broken away regulations, orders, social moral standards to the false-and-ugly abyss, if we do not deeply go into the rules of modeling and basic principles of art, pursing creation anew, bringing up individualism and hypocritical self-performance and trying to deconstruct all the traditional culture, value and order, and going after morbidly twisted inner freedom and outrageous weird.

Throughout the 1990s, those Chinese artists and younger art college graduates who come out from the generation of 1985 always insist on efforts to find the local personalities which differ from Western tradition. Even it is from other styles or techniques, it should independent personality in dealing with local issues. At that time, the dramatic changes and a lot of social phenomenon in China can be the subjects of creation, and the honor from the world encourages this personality. These factors at least stimulate a large number of shocking works on the surface. During this period, the passion of Chinese art is too much for the whole world.

When we learn from painters, we should grasp measurements and understand the trend of the times, but not give up the fundamental, just like Zhang Xiaogan who shows the capability of emotion and courage of self-control in art. When we appreciate them, we should treat them just like the most of the artists that need a kind of self-resistance to make a distance with the society. And this distance makes his works achieve a new narrative point of view and way in the contemporary art of hustle and bustle. "Expression of Chinese painting personality may be different in painting the charm. A kind of feeling, which basic things are the same, what the difference is that how people attach his own thoughts to achieve own characteristics in painting. Chinese literati ink are in the same way with prose, especially focus on mood to devote themselves to excavating the spiritual world, which beauty of it cannot explain in words, only by sense. European paintings, mainly emphasizes sensory impressions which are their contents." [3] In general, the common thing is that the expression of individuality is different.

In the process of drawing, we often understand the personality as self-transformation of artistic intention. In fact, personality is the expression of natural style, which is formed in constant practice of painting. Everyone will unconsciously have their own personality. Cezanne emphasized structure and decent painting; Picasso focuses on decomposition form of 
Cubism; the feeling of Raphael's paintings is a kind of simple and straightforward beauty. Everyone has own characteristics.

\section{THE UNITY OF BASIC SKILL TRAINING AND THE CHARACTERISTIC EXPRESSION}

Basic skill training is the basis of the characteristic expression, and the expression of characteristic is a manifestation of the way of basic training. Now for us to do much practice in basic skill training in order to develop the painting quality, in the later painting has a good foundation. If the expression of characteristic is a flower, basic skill training is the root, flower always depends on the roots to absorb nutrients and moisture. Picasso started to make sketch before the age of seven, to his later creation has a great influence. It was his deep basic of drawing so that he can become a master in the painting. In China, Shitao is known as "China's Cezanne", "the father of modern art in the history of Chinese painting", why? Because he combines basic skills (including theory) with characteristic nicely.

Huang Yongyu mentioned in his readme "art is different from science. Scientific law is the law of progress and art painting is more and more prosperous and rich. No progress to speak of art, painting essentials without such progress, all is a hands-on person, must rush to complete a century of life in a short space and time, for a person to start over again, painting is the result of a lifetime of adventure. " ${ }^{[4]}$. This passage seems to deny this point of basic training of theoretical basis in painting. In fact, the painting can also be described by progress. Each painting to all human experience in the past continued to improve and divergent thinking, and enhance the level of painting. If there is no basic training, as discarded crutches, the screen has no direction which prompt by" geometry ", seems to have lost the map guide, a piece of paper without relying on at a loss. How to express the characteristic? Some people say that this is more space to play, more freedom to speak, I think, may only be created out of random graffiti painting of ruffian make it! We reached a consensus on cognition of the common law in painting, to respect the arts, law and character. Because the law has the universal value, only in this can to open up a vast world of artistic vision, initiate ego artistic individuality from the artistic commonality effectively. Any artistic creation, regardless of category, genre, form, can not be contrary to the basic laws of artistic creation and escape the constraint of the basic rules of art.

\section{CONCLUSION}

We should pay equal attention to the basic skills training and individual expression and cannot neglect any of them, truly building individual houses in the solid foundation. Let our paintings stand the test and impact in the flow of history. In the undergraduate education stage, we should pay more attention to the relationship of basic skills training and expression of personality, grasp the chance to enrich ourselves and tap personal potential to lay a good foundation for future. Basic skills training and expression of personality are training contents at different stages, and training purposes are also different. As long as a good grasp of the scale between the two, not biased towards one, making the balanced development in the learning process, I think students will benefit a lot in painting.

\section{REFERENCES}

[1] Jiang Songping, School Education and Painting on the Shelf [J]Art Research2004(4),115.

[2] Zuo Na,The Role of Chinese Painting in the Construction of College Students' Aesthetic Frame[J]. Journal of Mudanjiang Normal College (PHILOSOPHY C AND SOCIAL SCIENCES) 2006(1),123.

[3] Diderot(with), Chen Zhanyuan translated. Diderot on painting[M]. Guilin: Guangxi Normal press, 2002, 56.

[4] Huang Yongyu. Self Narration of Huang Yongyu [M].Zhengzhou: Elephant Press,2004, 78. 